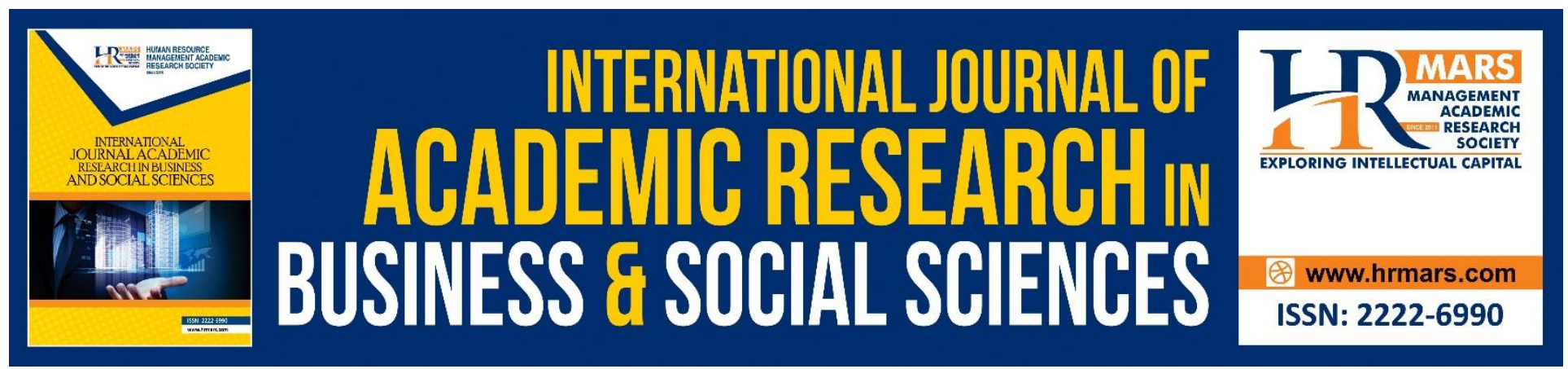

\title{
Association between Hospice Care and Family Satisfaction
}

\section{Rabia Arshad, Ali Waqas, Syeda Sidra Tasneem Kausar, Rubina Jabeen}

To Link this Article: http://dx.doi.org/10.6007/IJARBSS/v9-i3/5741

DOI: $\quad 10.6007 /$ IJARBSS/v9-i3/5741

Received: 02 Feb 2019, Revised: 17 Feb 2019, Accepted: 26 Feb 2019

Published Online: 09 March 2019

In-Text Citation: (Arshad, Waqas, Kausar, \& Jabeen, 2019)

To Cite this Article: Arshad, R., Waqas, A., Kausar, S. S. T., \& Jabeen, R. (2019). Association between Hospice Care and Family Satisfaction. International Journal of Academic Research in Business and Social Sciences, 9(3), 756-766.

\section{Copyright: (C) 2019 The Author(s)}

Published by Human Resource Management Academic Research Society (www.hrmars.com)

This article is published under the Creative Commons Attribution (CC BY 4.0) license. Anyone may reproduce, distribute, translate and create derivative works of this article (for both commercial and non-commercial purposes), subject to full attribution to the original publication and authors. The full terms of this license may be seen

at: $\underline{\text { http://creativecommons.org/licences/by/4.0/legalcode }}$

Vol. 9, No. 3, 2019, Pg. 756 - 766

http://hrmars.com/index.php/pages/detail/IJARBSS

JOURNAL HOMEPAGE

Full Terms \& Conditions of access and use can be found at http://hrmars.com/index.php/pages/detail/publication-ethics 


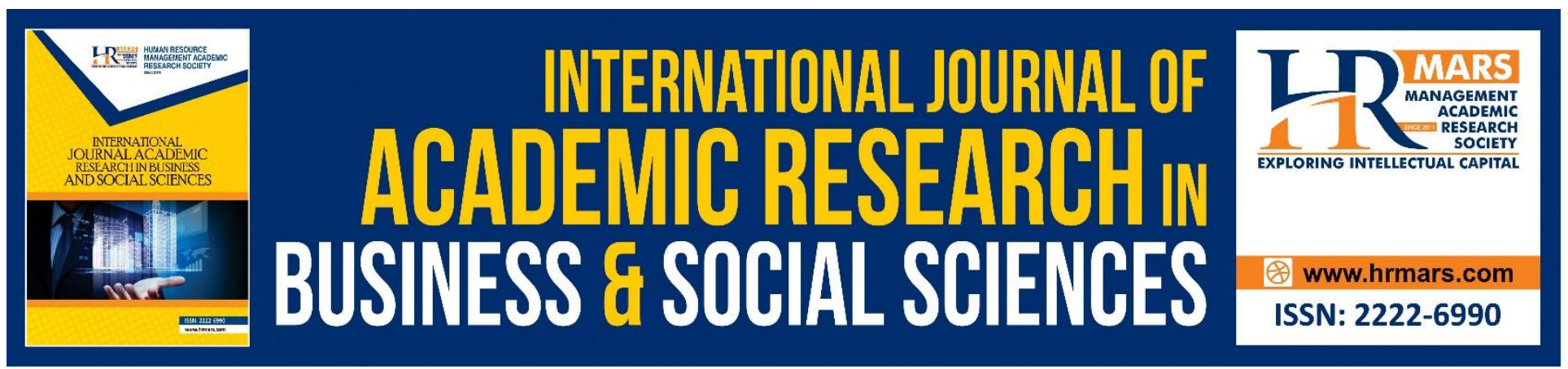

\title{
Association between Hospice Care and Family Satisfaction
}

\author{
Rabia Arshad ${ }^{1}$, Ali Waqas ${ }^{2}$, Syeda Sidra Tasneem Kausar ${ }^{3}$, \\ Rubina Jabeen ${ }^{4}$ \\ ${ }^{1}$ Post RN, Nursing College, the Superior College Lahore \\ ${ }^{2}$ Post RN, Nursing College, the Superior College Lahore \\ ${ }^{3}$ Director, Nursing College, the Superior College Lahore \\ ${ }^{4}$ Principal, Nursing College, the Superior College Lahore \\ Email: ali.90waqas@gmail.com
}

\begin{abstract}
Little is known about the associations between family satisfaction with end-of-life care and caregiver burden. We conducted a researcher-assisted questionnaire survey to clarify the impact of caregiver burden on family satisfaction and to determine the types of burden that decrease family satisfaction. The data collection tool developed by Colón \& Lyke, 2003 was used for this study. The results revealed that majority of participants were satisfied with hospice care. Tables are used to show the frequency percentage of participants' response. Majority $60 \%$ of participants were female and $40 \%$ were male. This study identified several comprehensive surveys aimed at measuring the experiences of end-oflife care, covering a variety of content areas and practical issues for survey administration. Future work should focus on standardizing surveys and administration methods so that experiences of care can be reliably measured and compared across care settings.
\end{abstract}

Keywords: Family Satisfaction, Hospice Care

\section{Introduction}

One of the most significant thing which hospice care has to look for is that what exactly a patient needs in his terminal days and; are those needs being properly met; is what should be the aim of hospice care providers. Satisfaction of the family members is another important milestone which has to be achieved by hospice team. If a patient is not satisfied with the services he is receiving, the family members feel insecure and are unhappy with the care. So for the achievement of maximum satisfaction level of families. it is thus very important to provide the patient not only the social and emotional assistance but also to spiritually strengthen him (Miceli \& Mylod, 2003).

A hospice care team should be distinctively furnished in responding to the ultimate needs of the patient in the most appropriate and efficient way so as to satisfy the family members. This 
requires not only providing what a patient needs but also a proper follow up. Steel et al, points out that there a sheer lack in the satisfaction of the family members and proper hospice care, this is because all the studies which have previously been conducted do not focus on large number hospice patients rather a few patients are selected secondly the influence of surroundings on the admission of terminally ill patients has not yet thoroughly been explored (Lendon et al., 2015).

Hospice care give the support to the patients who are at the verge of life and also to the families of those patients through a properly designed program in which they receive supportive treatment to reduce their pain and minimize the miseries they have to encounter during their last days. Member whom are to be particularly cantered are those who are closely related to the patients and are directly involved in lending their tiring efforts for the maximum ease of patient. Precisely speaking hospice care is for both the patients and family members, as the family members are directly affected mentally as well as physically by the ultimate non-ending miseries of the patient. So hospice care should be satisfying the family members in particular (Ong, Brennsteiner, Chow, \& Hebert, 2016).

The National Institute of Health (NIH 2016) defines the end of life care as the presence of a chronic disease or symptoms or impairments that persist but may also fluctuate; and the symptoms or impairments. Care and can lead to death. Hospice has made end of life care their priority with the goal of improving the quality of life for dying patients and their families. Improving the quality of life of the patient is another vital concern of hospice care which in no way could be neglected. It could also be taken as palliative care. The main emphasis of which should be the ultimate quality of life of the patient as well as the support of close family and friends. Effectiveness of the hospice care can be precisely assessed when the emotional injury of the patient which he is undergoing during the course of his uncured disease is taken into account while giving the care"(Doten, 2009).

Family member which voluntarily opt to stay at home to provide care to the patient under the supervision of hospice team is the primary caregiver and his satisfaction is the most important aspect of hospice care. The hospice team which includes nurses, doctor's social workers guide the primary caregiver regarding the medications as well the manoeuvres which shall improve the quality of life of the patient. This would help minimize the anxiety of family members and in alleviating their satisfaction and improving the quality of life of the patient at the same time. Fulfilling the needs of the primary caregivers by the competent hospice team in providing the care to the patient is one of the major tool which contributes to the satisfaction of family members (Engen, 2017).

\section{Aim of the Study}

- The aim of the study is to revise and repeat the fulfillment survey.

- To look for the level of satisfaction achieved by the caregivers.

- Most importantly to see how far the hospice team has been successful in achieving their goals to improve wellbeing of the patients who are at verge of death.

- Repeated checking of the gestures and methods used for wellbeing of patient directly associated with caregiver's satisfaction. 


\section{Problem Statement}

There is no tool or no efficient method devised which measure the could level of satisfaction of family members as in many cases family members themselves are unaware of what they need and what they have to demand. So there remain some met needs of family members hindering the measurement of level of satisfaction exactly achieved.

\section{Significance of Study}

Patients: One of the most compelling arguments for the study of hospice care making is the potential benefit for the patient. Patients are the recipients of the care provided by the care giver.

Health Care Provider: Improved understanding of hospice care and family satisfaction may result in improved decisions in the areas of assessment, planning, and intervention. The study finding, will help the health care provider to think positively and display positivism in their hospital environment in this way, they will begin to feel better about their career.

Organization: The Finding of the study might be helpful for the organization to develop the strategies to improve hospice care skills through training session, workshop, and seminar in result skills of care provider will be improve and ultimately this will improve the working environment and quality of care and in this way family satisfaction may be improved. It will be suitable for the hospice care providers to adopt beneficial steps for placating the loopholes and discrepancies in their services and then completely obliviating them.

Future Research: The result of this study will give direction to the future researcher to utilize this study as a literature and guidance. Additionally study will help them to identify the study gap.

\section{Hypothesis:}

\section{Null Hypothesis:}

1) There is no association between unstructured framework to the patient experience

2) There is no association between family satisfaction and hospice care

\section{Alternative Hypothesis:}

1) patients with prior ambulance experience will provide higher pride rating

2) There is association between the family satisfaction and hospice care

\section{Literature Review}

Previous studies on hospice care have proved that satisfaction of patients and family members has been achieved well came to the conclusion of their research that patients as well as family members had a satisfactory experience of hospice care. According to researchers "satisfaction can be measured and defined as Evaluation Based on the Fulfilment of Expectations. "Their research also showed that palliative care or hospice care helps in relieving or reducing the pain of the patient and also the grief suffered by their family members thus improving the quality of life of hospice patients in the last days of their lives (Lendon et al., 2015)

However, the research has one loophole which is that they don't have any sensitive method to check for the achievement of reliability. This method is often in the form of a survey which is conducted by giving handouts to the patients and their family members particularly the caregivers, 
evaluate their level of satisfaction in the end days of life of the patient Secondly the indirectly unforeseen factors which affect the admission of patients demanding hospice care has not been well established regarding the family satisfaction (Doten, 2009).

Numbers of deaths are markedly increasing all over the world for which the need of hospice care was realized. Not only the hospice care facilities have to be increased but the level of satisfaction of the family members and the patients receiving these services has also to be analysed to check the effectiveness and success of these facilities. Hospice care not only gives the physical relief to the patient but is also expected to give spiritual and emotional care. Previous researches in this context have been conducted to check the level of satisfaction of the bereaved family members and the terminally ill patients. In the study the main aim was to look for the contentment level of those who were directly involved in giving the hospice care services and those who were receiving these services. The needs of the dying patients must be considered in order to best help them in their last days which also helps in the achieving the satisfaction of the family members. The more the needs are unmet ,the higher is the level of dissatisfaction of the family members (Eyre, 2016).

It has been shown through the research that family member who look after the hospice patients need to be supported and assisted in all the aspect as this would help in improving the quality of life of the patients. patients who has lost their hopes and an undergoing increase anguish, suffering and hardships need to be taken care of by hospice service provides to completely satisfy the family care givers. The satisfaction of family members is directly associated with the patients mental and physical health in the end days of the life. But the main quandary is that family members themselves are completely not aware of all their psychosocial needs or they are unable to identify them clearly, so the hospice caregivers unable to full fill their needs whether psychosocial or spiritual which in turn results in their dissatisfaction and there remains a gap in proper care giving to the hospice patients. Their gap can only be reconciled by conducting proper and systematic research which covers all these aspects of patients care and family satisfaction (Engen, 2017).

There must be a proper understanding of end of life decision making processes with chronic conditions. Wishes of terminally ill patients must be considered and properly addressed so as to reduce their pains to some extent in their last days. This would directly augment the satisfaction of the family members. Plans should be made according to patient's wishes and needs but conversation should be made with the family members (Glaudenans, Charante and Williams, 2015]

A systematic review of the literature by Brereton et al has demonstrated the inadequacies of the hospital environment in providing palliative care. These factors are becoming key drivers at a policy level to reduce acute hospital admissions amongst patients with a life limiting illness. However what is missing in this debate is how patient and families experience palliative care in hospital (Brereton et al., 2012).

In the conclusion, "Hospice care is associated with better symptom relief, patient-goal attainment, and quality of end of life care. Encouraging earlier and increased hospice enrolment may improve end of life experiences for patients with cancer and their families." (Skolarus et al., 2014).

A study published in 2003 in Japan and results revealed that the ninety percent of respondents were satisfied with nursing care. Eighty percent were satisfied with the information they received at admission, $70 \%$ were satisfied at the critical phase, and $63 \%$ were satisfied at the end of life. The main expected types of desirable terminal care were pain management and spiritual care. The bereaved 
had difficulty dealing with patients' pain, dyspnea, and appetite loss. Forty-four patients were treated with narcotics. Fifty-seven percent of the family members of these patients found pain to be the most difficult symptom to deal with. Fifty-eight percent of the respondents believed that if narcotics were used, patients would soon die (Ogasawara, Kume, \& Andou, 2003).

\section{Research Methodology}

This research has two variables, social media (Family satisfaction) and depression (Hospice care). That is why the questionnaire used in this research was adopted from two articles. The four scale questionnaire for exposure to social media was adopted from the article social media and academic performance of students Peter, 2015 and depression assessed by 6 item scale which was adopted from the article mobile phone dependency and its impacts on adolescents' social and academic behaviours (Seo, Park, Kim, \& Park, 2016; J.-k. Seo et al., 2016). The questionnaire was isolated into two parts (A and B). Section A contained for collection of personal data of respondents while Section $B$ comprised of five scale Likert scale that elicited responses from the respondents with response options: Strongly disagree (SD), Disagree (D), Neutral(N),Agree(A) to Strongly agree (SA).

\section{Data Collection Plan:}

Information series plan is one of the predominant sources to collect data. A self-administered questionnaire may be used to gather facts from the observe participants. There could be given a free hand to finish it and return it.

\section{Data Analysis:}

Statistics analysis might be performed by SPSS version 20. statistical computer software program for records evaluation this is a descriptive observe and all of the descriptive information will be acquired through the SPSS software program.

\section{Including Criteria}

- Patients relative

- Male and female

- Willing to participate

- Those who understand English

\section{Results}

This study is conducted at Sheikh Zayed Hospital to assess the relationship between family satisfaction and hospice care. The result of this study distributed into two sections, first section is statistics of demographic factors, and second section is statistics of self-administered questionnaire contained 27 items.

\section{Demographic Analysis}

Table 1 shows that the gender of participants and results revealed that the majority 60 (60\%) female and $40(40 \%)$ male were participating in this study 
INTERNATIONAL JOURNAL OF ACADEMIC RESEARCH IN BUSINESS AND SOCIAL SCIENCES Vol. 9, No. 3, March, 2019, E-ISSN: 222 2-6990 @ 2019 HRMARS

Gender : Table 1

\begin{tabular}{|l|c|c|c|c|}
\hline Gender & Frequency & Percent & Valid Percent & $\begin{array}{c}\text { Cumulative } \\
\text { Percent }\end{array}$ \\
\hline Male & 40 & 40.0 & 40.0 & 40.0 \\
Female & 60 & 60.0 & 60.0 & 100.0 \\
Total & 100 & 100.0 & 100.0 & \\
\hline
\end{tabular}

Table 2 shows that the 100 participants participate in this study and majority 72 (72\%) were married and only 28 (28\%) were unmarried.

Biographical Table 2

\begin{tabular}{|l|c|c|c|c|}
\hline & Frequency & Percent & Valid Percent & $\begin{array}{c}\text { Cumulative } \\
\text { Percent }\end{array}$ \\
\hline Married & 72 & 72.0 & 72.0 & 72.0 \\
Single & 28 & 28.0 & 28.0 & 100.0 \\
Total & 100 & 100.0 & 100.0 & \\
\hline
\end{tabular}

Table 3 shows that the majority 77 (77\%) participants stay is less than 1 year and 14 (14\%) participants stay is $1-5$ years, $6(6 \%)$ participants stay is $6-10$ years and only $3(3 \%)$ participants stay is more the 10 years.

\section{Stay in Organization}

Table 3

\begin{tabular}{|l|c|c|c|c|}
\hline Stay in Organization & Frequency & Percent & Valid Percent & $\begin{array}{c}\text { Cumulative } \\
\text { Percent }\end{array}$ \\
\hline Less Than 1 Year & 77 & 77.0 & 77.0 & 77.0 \\
1-5 year & 14 & 14.0 & 14.0 & 91.0 \\
6-10 year & 6 & 6.0 & 6.0 & 97.0 \\
Above10 year & 3 & 3.0 & 3.0 & 100.0 \\
Total & 100 & 100.0 & 100.0 & \\
\hline
\end{tabular}

Frequency of self-administered questionnaire

\section{Validity of Self-Administered Questionnaire}

Data was collected from 100 participants to determine the relationship between family satisfaction and hospice care. Data was loaded to the SPSS software for the Initial analysis. The Kaiser-Meyer Olkin (KMO) and Bartlett\&\#39. Test measure of sampling adequacy was used to examine the appropriateness of Factor Analysis. A factor includes, family satisfaction and hospice care were analyzed individually, and results are mentioned below.

Validity of family satisfaction 
Table 4 shows that the validity of 5-point Likert scale questionnaire for family satisfaction. Taking a $95 \%$ level of Significance, $\alpha=0.05$ and results revealed that the approximate of Chi-square is 128.981 with 15 degrees of freedom, which is significant at 0.05 Level of significance. The KMO statistic of 0.666 is also large (greater than 0.50). Hence Factor Analysis is considered as an appropriate technique for further analysis of the data.

KMO and Bartlett's Test family satisfaction

Table 4

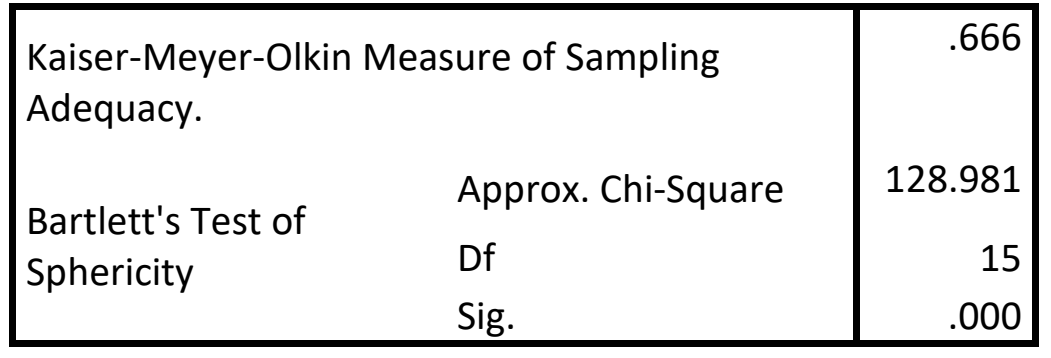

\section{Validity of Hospice Care}

Table 5 shows that the validity of 5-point Likert scale questionnaire for hospice care. Taking a 95\% level of Significance, $\alpha=0.05$ and results revealed that the approximate of Chi-square is 822.301 with 276 degrees of freedom, which is significant at 0.05 Level of significance. The KMO statistic of 0.606 is also large (greater than 0.50). Hence Factor Analysis is considered as an appropriate technique for further analysis of the data

\section{KMO and Bartlett's Test}

Table 5

\begin{tabular}{|c|c|c|}
\hline \multicolumn{2}{|c|}{$\begin{array}{l}\text { Kaiser-Meyer-Olkin Measure of Sampling } \\
\text { Adequacy. }\end{array}$} & .606 \\
\hline & Approx. Chi-Square & 822.301 \\
\hline Bartlett's Test of & df & 276 \\
\hline & Sig. & .000 \\
\hline
\end{tabular}

Table 4 shows the reaction of participants against item one that was "Ease of scheduling the initial hospice meeting" only 2 (2\%) participants go with strongly disagree, 5 (5\%) disagree, 14 (14\%) neutral and majority73 (73\%) were select agree and only 6 (6\%) were strongly agree.I

\section{Reliability Test Self-Administered Questionnaire}

Table 6 shows that the Instrument reliability, it has been tested for each variable separately calculated through Cranach's alpha identify that the reliability and how much it is reliable to use and replicate it by different researchers under different situation to get the reliable result and the results revealed that the value of Cronbach's alpha for 6 items family satisfaction is .660\% these results meet the standards requirement of reliability and this study variable is reliable and significant. The value 
INTERNATIONAL JOURNAL OF ACADEMIC RESEARCH IN BUSINESS AND SOCIAL SCIENCES

Vol. 9, No. 3, March, 2019, E-ISSN: 2222-6990 @ 2019 HRMARS

of Cronbach's alpha for 21 items regarding hospice care is .509\% these results meet the standards requirement of reliability and this study variable is reliable and significant.

\begin{tabular}{ccc}
\multicolumn{3}{c}{$\begin{array}{c}\text { Reliability Statistics } \\
\text { Table } \mathbf{6}\end{array}$} \\
\hline Factors & Cronbach's Alpha & N of Items \\
\hline Family Satisfaction & .660 & 6 \\
Hospice care & .509 & 21 \\
\hline
\end{tabular}

\section{Section B; Frequency of self-administered questionnaire}

Table 7 shows the reaction of participants against item one that was "Ease of scheduling the initial hospice meeting" only 2 (2\%) participants go with strongly disagree, 5 (5\%) disagree, 14 (14\%) neutral and majority $73(73 \%)$ were select agree and only $6(6 \%)$ were strongly agree.

\section{Discussion}

The ultimate family satisfaction with the services of hospice care providers remained one of the paramount goals of this study, along with other focuses. As far as family satisfaction was concerned, firstly, it was necessary to look if the families have achieved the desired level of satisfaction and secondly, proper identification of all those factors which contributed to augment and enhance the satisfaction of families was also the mainstay of this study. Third and unforeseen factor which should be considered of equal importance as others is about all the internal as well as external factors which directly influence family contentment. Each of these factors were consistently and closely monitored using a set of data and well-equipped questionnaires which were given to approx. 100 families. Their responses in context to the questions were then interpreted and compiled in the form of data which ultimately explained the level of satisfaction attained by the families of hospice patients.

Most positive impression which revealed after such thorough study was that hospice care providers should be present round the clock to the patient as well as during peak stress moments they should also help in cancelling the close family members and boost their morals. A flexible and unyielding behaviour of the was team was very well appreciated and acknowledged. This gesture left clear impression on the families the hospice care benefited them in real sense and it was good decision on their part to opt for these services. Apart from this, there were few issues which were pointed out after getting through different feedbacks from the families and these issues should be rectified at the earliest to alleviate the scores as well as satisfaction levels of the families. couple of issues which received the highest criticism were, the least interest of primary hospice personal who made the initial arrangements for hospice services and the training of family members was also not up to the mark by hospice care providers. Considering other rooms of hospice services, it was generally observed that fairly high level of contentment was shown by the close family members.

\section{Conclusion}

It has been found that satisfaction of the family members depend on myriads of important directly as well as indirectly influencing factors which predominantly include, entire focus on the patient in his end days of life, educating and looking after the family members during their extreme stress hours as well as their proper time to time counseling, systematic and symptomatic treatment of the patient 
relieving his pain to the maximum extent. Concluding the discussion, it was found that rectifying few of the issues by providing suitable remedy plans for them and providing the best possible services to the patient helped achieving the maximum satisfaction of the family members

\section{Limitations}

This study had numerous limitations which predominantly were...

$>$ Time span was too short.

$>$ The study design is convent sample technique.

$>$ Likert scale questionnaire has been used in this study.ss

$>$ Data collection faced lot of issues.

$>$ The respondents of the examination have extremely thoughtless demeanor with respect to filling questionnaire. Participants of study have no clue about the significance of the filling poll truly.

\section{Recommendations}

Hospital management need to:

$>$ Encourage and support to care provider for post basic trainings / sub-specializations to increases knowledge and skills base.

$>$ Consider knowledge and skills obtained through post basic trainings and / or sub-specializations when deploying care provider.

$>$ Enable nurses exercise clinical decision-making as taught and this be included in hospital policies and protocols.

$>$ Actively support reasonable decisions made by hospice care team more research needs to be done.

$>$ Identify what other aspects of the clinical environment affect family satisfaction regarding hospice care. Identify other causes for deteriorating health care services in the hospital.

\section{References}

Brereton, L., Gardiner, C., Gott, M., Ingleton, C., Barnes, S., \& Carroll, C. (2012). The hospital environment for end of life care of older adults and their families: an integrative review. Journal of Advanced Nursing, 68(5), 981-993.

Colón, M., \& Lyke, J. (2003). Comparison of hospice use and demographics among European Americans, African Americans, and Latinos. American Journal of Hospice and Palliative Medicine ${ }^{\circledR}, 20(3), 182-190$.

Doten, K. M. (2009). Patient and caregiver satisfaction with end-of-life care: a need for instrument validity.

Engen, N. (2017). Interventions to Alleviate the Psychosocial Needs of Hospice Family Caregivers: A Systematic Review.

Eyre, V. E. M. (2016). Understanding the holistic impacts of hospice care on individuals who access their services. 
Lendon, J. P., Ahluwalia, S. C., Walling, A. M., Lorenz, K. A., Oluwatola, O. A., Price, R. A., . . Teno, J. M. (2015). Measuring experience with end-of-life care: a systematic literature review. Journal of pain and symptom management, 49(5), 904-915. e903.

Miceli, P. J., \& Mylod, D. E. (2003). Satisfaction of families using end-of-life care: Current successes and challenges in the hospice industry. American Journal of Hospice and Palliative Medicine ${ }^{\circledR}$, 20(5), 360-370.

Ogasawara, C., Kume, Y., \& Andou, M. (2003). Online exclusive: family satisfaction with perception of and barriers to terminal care in Japan. Paper presented at the Oncology nursing forum.

Ong, J., Brennsteiner, A., Chow, E., \& Hebert, R. S. (2016). Correlates of family satisfaction with hospice care: general inpatient hospice care versus routine home hospice care. Journal of Palliative Medicine, 19(1), 97-100.

Seo, D. G., Park, Y., Kim, M. K., \& Park, J. (2016). Mobile phone dependency and its impacts on adolescents' social and academic behaviors. Computers in human behavior, 63, 282-292.

Seo, J. K., Kang, K.-A., Kwak, J.-y., Kim, H.-J., Song, H.-j., Yoo, S.-S., . . . Park, M.-K. (2016). Portable device comprising a touch-screen display, and method for controlling same: Google Patents.

Skolarus, T. A., Wolf, A., Erb, N. L., Brooks, D. D., Rivers, B. M., Underwood, W., ... Slovin, S. F. (2014). American Cancer Society prostate cancer survivorship care guidelines. CA: a cancer journal for clinicians, 64(4), 225-249. 